\title{
J. J. Thomson Goes to America
}

\author{
Kevin M. Downard \\ School of Molecular and Microbial Biosciences, The University of Sydney, Sydney, Australia
}

Joseph John (J. J.) Thomson was an accomplished scientist who helped lay the foundations of nuclear physics. A humble man of working class roots, Thomson went on to become one of the most influential physicists of the late 19th century. He is credited with the discovery of the electron, received a Nobel Prize in physics in 1906 for investigations into the conduction of electricity by gases, was knighted in 1908, and served as a Cavendish Professor and Director of the laboratory for over 35 years from 1884. His laboratory attracted some of the world's brightest minds; Francis W. Aston, Niels H. D. Bohr, Hugh L. Callendar, Charles T. R. Wilson, Ernest Rutherford, George F. C. Searle, Geoffrey I. Taylor, and John S. E. Townsend all worked under him. This article recounts J. J. Thomson's visits to North America in 1896, 1903, 1909, and finally 1923. It presents his activities and his personal impressions of the people and society of the U.S.A. and Canada, and the science of atomic physics and chemistry in the late 1800s and early 1900s. (J Am Soc Mass Spectrom 2009, 20, 1964-1973) (C) 2009 American Society for Mass Spectrometry

$\mathrm{J}$ oseph John (J. J.) Thomson was born in suburban Manchester in England on December 18, 1856 and lived with his family in Plymouth Grove. He was born in an era where there were no bicycles, no motor cars, no telephones, no radio (wireless), no electric light, and "no germs, at least none recognized by the doctors" [1]. His great-grandfather Ebenezer Thomson hailed from Scotland, and ran a small bookselling business in Cheetham near where J. J. Thomson was later born. J. J. Thomson's father, Joseph James Thomson, also ran a profitable bookstore in Manchester. Joseph had intended for his eldest son to be an engineer, but the long waiting list for apprentices to Sharp-Stewart and Company, a firm of locomotive makers, led him to send his son to Owen's College. Here he was taught English, Latin, history, and mathematics [1]. He was also introduced to natural history, aided by a microscope his father had given him, having become very interested in nature [1]. In later life, Thomson confessed he would have been a botanist if he had his life over.

Thomson married Rose Paget in 1890. Rose was a twin daughter of Sir George Paget, the Regius Professor of Physic at Cambridge from 1872. His brother James was a prominent physician and surgeon who had a distinguished career in medicine and after whom Paget's disease is named. Rose, typical of women of her generation, received very little formal education, but was tutored in mathematics and science by her father, with whom she was very close. The Thomsons had two children, George Paget Thomson and Joan Paget Thomson, who were born 11 years apart, interrupted by the birth of a stillborn child. Their son George followed in

Address reprint requests to Dr. Kevin Downard, School of Molecular and Microbial Biosciences G-08, The University of Sydney, Sydney, NSW 2006, Australia. E-mail: kdownard@usyd.edu.au his father's footsteps and was appointed a Professor of Physics at Cambridge. He was awarded the Nobel Prize in Physics in 1937.

J. J. Thomson's educational opportunities and abilities meant he spent all his life in Manchester and Cambridge. He won a scholarship to study mathematics at Trinity College in 1876. He subsequently studied for the "Mathematical Tripos". The examination, taken after three years, consisted of 15-20 three-hour exams, sat over a period of three weeks. Thomson achieved the second best result in 1880, and was thus named the "Second Wrangler." He subsequently received a fellowship at Trinity to perform research work in mathematical and experimental physics under the direction of Lord Rayleigh (John William Strutt, the third Baron of Rayleigh), the then Cavendish Professor [2]. He soon devoted his attention to the discharge of electricity through gases, a subject that occupied much of his working life and culminated in his receipt of a Nobel Prize in Physics in 1906 "in recognition of the great merits of his theoretical and experimental investigations on the conduction of electricity by gases." He was credited with the discovery of the electron, though this has been challenged [3]. He was made a lecturer at Trinity in 1883 and a year later, at the age of just 27 , he was made the first Cambridge Professor of Experimental Physics despite a reputation for being a clumsy experimentalist (Figure 1). He assumed the role of Director of the Cavendish Laboratory that year and held it until he relinquished the post to Ernest Rutherford in 1919.

Despite being firmly rooted in Cambridge throughout his life, Thomson enjoyed the occasional opportunity to travel abroad, and no more so than to North America. This was due in part to his preference to travel to countries that spoke English. Although he could read French and German, he did not speak either, nor have 

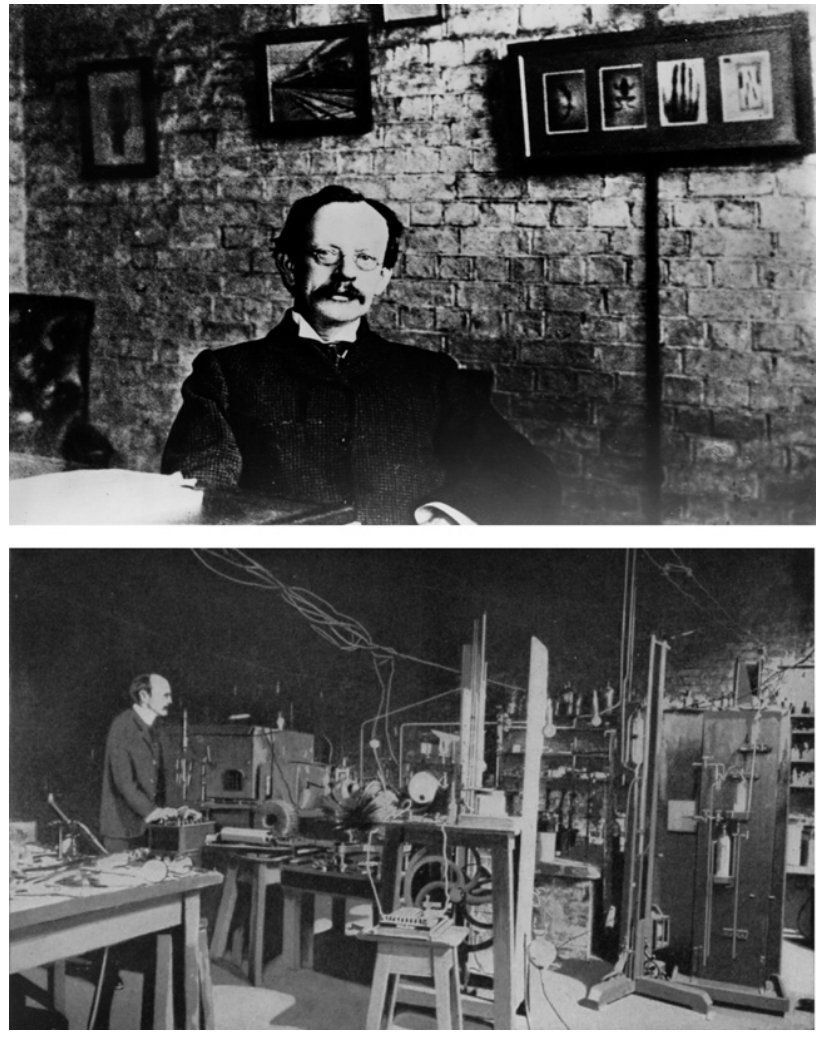

Figure 1. A young J. J. Thomson in his office (top) and laboratory (bottom), ca. 1890. Source: American Institute of Physics and The Project Gutenberg eBook of The Outline of Science, Vol. 1, by J. Arthur Thomson.

an ear for spoken language, claiming others spoke too fast [4]. Thomson was uncomfortable with not being understood, and with not understanding others, that prevented him from taking his holidays in Europe [5, 6].

\section{Welcome to New York}

In October 1896, following an invitation to take part in the sesquicentennary celebrations of Princeton University and give a series of lectures, J. J. Thomson traveled to the United States for the first time, accompanied by his wife Rose. They sailed aboard the Campania (Figure 2), a liner built for the Cunard Steamship Company that made its first voyage from Liverpool in 1893.

In an episode that could easily be relived today, J. J. Thomson was met with some suspicion upon his arrival in New York. There had been some bombings in the area at the time, and home-made explosive devices had been used [7]. Thomson was carrying several cardboard cylinders in his suitcase containing copies of speeches he was to present during his visit. Quickly identified as a "foreigner" and challenged about the cylinders by customs officials, Thomson was unable to convince the inspectors that his trip was legitimate, as they had not heard of Princeton University. With their refusal to allow his baggage through, J. J. Thomson asked to speak to a supervisor who, recognizing his colleagues' igno- rance and Thomson's stature in the scientific community, promptly cleared them to travel [1].

The morning after their arrival, the Thomsons traveled to Baltimore to stay with friends Harry Fielding Reid and his wife Edith. In the autumn of 1885, Reid, his wife, and mother-in-law had lived in Cambridge for the better part of a year [8]. Harry Reid had worked at the Cavendish during this time and developed a strong friendship with the new Director, which had endured thereafter. Of a similar age, Reid held an academic appointment in the Geology Department at John Hopkins University, where he established a reputation in geophysical research, particularly seismology. The Reids lived in a large townhouse on Cathedral Street in the heart of Baltimore society [8]. The Thomsons' stay allowed them to experience both the academic and social life of Maryland. The Reids had an AfricanAmerican servant who had been with the family for many years and chose to remain with them after the abolition of slavery. Thomson was unsure how to address the man and was reminded of Booker Washington's practice of referring to his fellow African-American's as "uncle." Thomson felt uncomfortable using this term himself, so he decided to address the man instead as "Professor" [1].

After their short stay in Baltimore, the Thomsons were taken to a baseball game as part of their introduction to American culture. J. J. Thomson was surprised to see that the crowds were so vocal in their enthusiasm for the game, and he was impressed by the pitcher's ability to put a spin on the ball. He likened the game to rounders and was impressed that it reached "a standard but rarely obtained in English cricket" [1]. Although more of a keen spectator than sportsman himself, Thomson wrote "I always myself get very much excited by a keen contest and feel for the moment that nothing on earth matters as much as the side I am interested in should win." He also recalled favorably the hospitality and informality he experienced; "I have never been in a

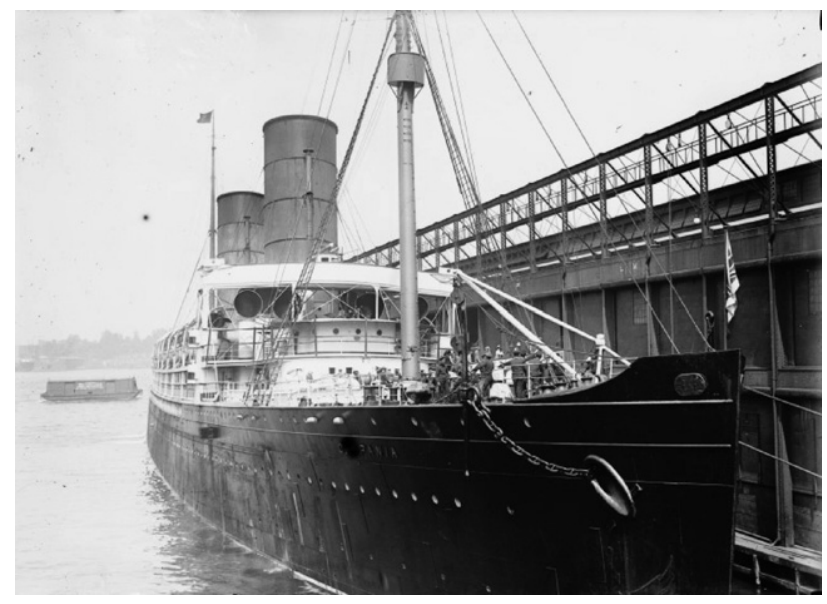

Figure 2. Campania, on which J. J. Thomson first sailed to America, birthed at the Cunard pier in New York. (Source: Wikipedia). 
city where the hospitality was more charming, more generous, or more intimate than that of Baltimore" [1].

\section{Presentation Speech at Princeton's Sesquicentennary}

The Thomsons traveled to Princeton to take part in the sesquicentennary celebrations and stayed with Henry Burchard Fine, a Professor of Mathematics at Princeton. A 3-day holiday had been proclaimed to celebrate the sesquicentennary of the college (known then as the College of New Jersey) and to confirm its new official name.

That afternoon, J. J. Thomson addressed the gathering as a representative European Universities at the celebrations. His speech extolled the achievements of three Princeton scientists: physicist Joseph Henry, geologist Arnold Guyot, and astronomer Charles Young [9]. "I rise to offer to Princeton University on behalf of the universities and societies of Europe a hearty congratulation.... I was told long ago by Cambridge men that they never felt more at home than when they were at Princeton. I, since I have been here, have felt that feeling myself strongly.... The labors of Princeton men during the last 150 years command the gratitude and consideration of every university and society.... To the historian, the lawyer, the politician, and the man of science, Princeton is classic ground. Apparently, political events took place here of incalculable importance to this country, and which an Englishman can now heartily acknowledge were settled in the way to best promote the peace, happiness, and prosperity of the world.... No man of science can forget that Princeton shares with the Royal Institution of London the honor of being the seat of the greatest discoveries, very important in electricity. It was here that (Henry) discovered the phenomena of electrical vibration, although its importance was not appreciated until it had been rediscovered a few years ago. To Princeton belongs the honor of establishing the first chemical laboratory in this country; and that great discoverer and philosopher, Guyot, has engraved the name of Princeton upon this planet. ... The researches of Young on the sun have caused the name of Princeton to be forever associated with the very center of the solar system" [9].

Thomson later recalled that he found Princeton to be the American university most reminiscent of Cambridge. "It was not surrounded by workshops or shops, but by spacious lawns studded with fine trees, which recall the Cambridge backs. The gateway to one of the courts is copied from the Great Gate at Trinity (College). When I last visited Princeton after an interval of more than 20 years, I found the resemblance still greater" [1].

The main events of the second day were a convocation in the morning, a football game in the afternoon in which Princeton trounced the University of Virginia $48-0$, and a torchlight procession at night. The third day concluded with a word of thanks to delegates from
President Francis Patton who announced that despite the economic depression of the day, an endowment had raised more than \$US $1 \mathrm{M}$ for new professorships, fellowships, a library, and a new dormitory [10].

\section{Princeton Lectures on Cathode Rays and Corpuscles}

While at Princeton, J. J. Thomson gave a series of four well-attended lectures entitled "The Discharge of Electricity Through Gases". These were published, with some additions, 2 years later [11]. In his lectures, he discussed the discharge of electricity in gases, the photoelectric effect, and the nature of cathode rays. In the published version of the lectures [11] he writes, "Two widely divergent views of the nature of cathode rays (exist). The one view, which was first advanced by Goldstein, ... is that cathode rays are waves in ether.... The other theory, which was first advocated by Crookes, regards cathode rays as marking the course of a stream of negatively electrified particles, these particles, unless acted upon by magnetic force, moving in straight lines and at high speed away from the cathode... (called) the corpuscular theory.... As long as we confine our attention to the phenomena inside the tube, the corpuscular theory seems to give the simplest, and indeed in some cases the only, explanation" [11]. On the nature of the rays, he writes, "when we catch the cathode rays, we catch at the same time a charge of negative electricity, and that, however we might pull the cathode rays about, we could not dissociate them from the negative charge" [11]. He goes on to state "this result brings us face to face with the question what, on the corpuscular theory, are the carriers of the negative charges? Are they the molecules of gas; or the atoms; or are they matter of some other state of aggregation; and if so, is this state of aggregation coarser or finer than the atomic state?" [11]. Based on the experiments conducted by Lennard, Thomson argues "a large aggregation of molecules would behave like a solid moving through the gas, and the distance it traveled before its momentum fell ... would be inversely proportional to the coefficient of viscosity... (or) density of the gas; thus if the carriers were aggregations of a large number of molecules, the cathode rays ought to travel as far in the gas at a high-pressure as in a gas at a low one, and this is not the case.... Thus, as the carriers are not larger than the molecules, there remains the alternative that the carriers are small compared with ordinary atoms or molecules; and this assumption is consistent, I think, with all we know about the behavior of these rays" [11].

Thomson then describes his own experiments designed to obtain some information of the size of these carriers of electricity. Using his cathode ray tubes, he was able to measure the ratio of mass-to-charge of the corpuscles at $1 / 500$ of the value of hydrogen. Thus "either the charge carried by the corpuscle must be greater than that 
carried by the ion of an electrolyte, or the mass of the corpuscle must be very small compared with that of the ion. The results of this investigation thus support the view that in the corpuscles in the cathode rays we have a matter in a finer state of subdivision than the ordinary atom" [11]. The 2 years that passed between his lectures and their publication may have crystallized Thomson's thoughts and changed his opinions of this. One of those who attended Thomson's lectures at Princeton has recounted that he had a very different view at the time from those published later in 1898. Henry Crew wrote of these discrepancies, "those who listened to the lectures of Professor J. J. Thomson in the autumn of 1896 will recall with surprise-not to say astonishment-with which was received his clearly stated experimental evidence for thinking that the carriers of electrification, through gases at ordinary pressure, are aggregations of atoms, large compared with a molecule of gas, so large, indeed, that they can be filtered out with glass wool. In striking contrast with this stands the principal result of his investigations during the 3 years that have lapsed since the Princeton Sesqui-centennial, viz., that in gaseous discharges at low pressures the negative electrification is carried by particles of matter- "corpuscles" he calls them-whose mass is of the order of one thousandth of the mass of a hydrogen atom" [12]. Crew though was quick to qualify his comments so that any reader ought not to construe "that the director of the Cavendish laboratory has, for a moment, forgotten to draw a sharp line between the results of experiment and the results of imaginationeven of the scientific imagination" [12].

On the Friday night before leaving Princeton, the invited visitors to the sesquicentennary celebrations attended a dinner at the university club. J. J. Thomson was seated next to a New York physician [1] who recommended a cure for sea-sickness if Thomson or his wife were to experience it on their sea voyage home. "As soon as you get settled on board," he said, "have a Manhattan cocktail and then slowly nibble dry biscuits. As soon as you feel it an effort to do this, take another cocktail ... and so on. The theory of it is that you will be all right as long as you can take the biscuits; the cocktails are to make you want to do this."

The Thomsons failed to take the advice on their return to England on the Lucania on what was an uneventful passage. They arrived back in Cambridge in early November [6].

\section{First Return to the U.S.}

Thomson's second visit to the United States occurred in the spring of 1903. On this occasion he sailed alone, arriving in May. He went to give a course of five lectures on electricity and matter at Yale University, supported with funds provided by the Silliman Foundation. The funds covered Thomson's travel from England and his accommodation at the Graduate's Club. This enabled him to interact with many of the univer- sity's academics during his visit. He wrote home to his son George Paget from the Club on May 22, 1903. "The son of one of the professors here, who is only seven years old, wanted to attend my lectures, but was told he would not understand them. I met with him and had a talk ... one afternoon. When I had gone, he told his mother he thought it was a great shame he had not been allowed to go to the lectures for he had had a talk with Professor Thomson and could understand what he said as well as he could anyone else" [6].

Thomson arrived in New Haven during a strike by tramcar drivers [1]. University students had volunteered to break the strike by acting as drivers during peak hours so that their fellow students could make their classes. The tramway men protested and demanded that the university president Arthur Twining Hadley forbid it. He refused to do so and the situation became very tense between the drivers and their employers. At one point, gunshots were fired in anger.

Besides the transport strike, an outbreak of typhoid in the town prompted the local paper to blame the water authority for not taking adequate steps to prevent it. The water authority manager defended his position to Thomson while visiting the university club one evening, claiming that no contagion could have made its way into the water supply since it was fed from a stream by means of a waterfall of some six feet high and that "no microbe could possibly have fallen down it without breaking its blooming neck" [1]. Characteristically, the beauty of the local flora distracted Thomson from the town's problems, and, in any event, the tramcar dispute was resolved before his departure in the summer. "When I arrived in New Haven, the spring flowers ... were at their best. Bluetts, a flower something like a tritelia, were very plentiful and there were great drifts of a red-and-yellow aquilegia, neither of which would grow in England. The spring, however, only lasted for a short time and before the end of my stay was followed by a heat wave. This was tolerable in New Haven, as by taking a tramcar just before going to bed one could get cooled down and able to sleep without difficulty" [1].

His lectures were published the following year [13] and have recently been re-published [14]. As Thomson states, "my object in these lectures is to put before you in as simple and untechnical a manner as I can some views as to the nature of electricity, of the process going on in the electric field, and of connection between electrical and ordinary matter, which has been suggested by the results of recent investigations" [13]. The lectures presented representations of electric fields by lines of force, his views on the atomic structure of electricity, and the constitution of the atom.

Thomson's "plum pudding model" of the atom at this time consisted of a uniformly charged sphere or cloud of positive electricity (the "pudding") in which discrete corpuscles of negative charge (the "plums") were equally dispersed about the sphere to balance the positive charge and neutralize the atom [15]. These 
corpuscles maintained their positions due to their repulsion from one another. After addressing the conditions required for both a static and rotating ring of equally spaced corpuscles in the atom, Thomson proceeded to consider the forces acting upon any single charge when slightly displaced from its equilibrium position. He argued that in order for a ring distorted from its circular shape to remain stable, the individual charges in the ring must oscillate about their equilibrium positions with specific frequencies. Using a series of reasoned calculations, Thomson showed that a ring containing more than six corpuscles would be unstable, and that atoms containing many corpuscles would exist with them positioned in a series of concentric shells, with a greater number of charges in the outer rings and fewer charges occupying the inner rings.

On the number of corpuscles per atom, he argued in 1906 [16] that based on current experimental data obtained from the dispersion of light, the scattering of $X$-rays, and the absorption of $\beta$-rays by various gases, the number of electrons in an atom is on the same order as its atomic mass number. Thomson wrote "although no one of the methods can ... be regarded as quite conclusive by itself, the evidence becomes very strong when we find that such different methods lead to practically identical results."

Thomson's lectures were well attended, and a number of the students attending the lectures later spoke with him about their sporting interests [1]. He also heard that similar rivalries to those in England existed between American universities. "The rivalry between Yale and Harvard is quite as keen as that between Cambridge and Oxford and shows itself in unconventional ways. I saw at the house of one of the Professors a dog who had been trained to pretend to be sick whenever he heard the name Harvard [1]. Thomson also noted similarities between the architecture at Yale and that in Cambridge and was pleased to learn from his former pupil John Zeleny that the salaries of professors in America had improved since his first visit. "When I first went to America in 1896, these were quite inadequate (then approximately $£ 500$ pa.). Unless a professor or his wife had private means, it was impossible for them to live in even moderate comfort or for the wife to have any leisure from household duties. Benefactors were willing enough to leave money for buildings that would bear their names, but money for salaries was hardly procurable.... I believe that the normal salary of a professor is now about $\$ 6000^{\prime \prime}$ [1].

After his time at Yale, Thomson traveled again to visit Harry Reid and his wife for a few days at their summer house near Gettysburg, Pennsylvania. He returned to Cambridge toward the end of June.

\section{BAAS Meeting in Canada}

Having been elected President of the British Association for the Advancement of Science (BAAS) in 1909, J. J. Thomson set off to Canada in late summer, on August
13 [6], to lead a delegation of British scientists to the 29th annual meeting of the BAAS in Winnipeg [17]. The year prior, Thomson had been knighted by King Edward VII following his award of the Nobel Prize in Physics in 1906 in recognition of his theoretical and experimental investigations on the conduction of electricity by gases. Accompanied by his wife Rose, younger brother Frederick, and son George, the family sailed aboard the Empress of Ireland from Liverpool to Quebec up the St. Lawrence River to the walled city. The family spent the evening in Quebec walking about the old town, where then 51 year old J. J. Thomson found the steep winding streets tortuous. The next afternoon, the family traveled by train to Montreal, staying for a few hours, before connecting for the journey to Winnipeg via Niagara, Chicago, St. Paul, and Minneapolis [6].

The BAAS annual meeting was opened by Winnipeg mayor William Evans on the evening of August 25 with close to 1500 in attendance $[14,17,18]$. It was also noted by the press that of visiting scientists, J. J. Thomson was less well known to the general public than some of his contemporaries [18]. Thomson's presidential address [19] spoke first of the amazing rise of prosperity in Canada and the value of scientific research to that growth. For the remainder of his address, he presented an account of the recent developments of physics of the time from the discovery of the Röntgen rays, the study of gases exposed to these rays, the basis of electricity, electromagnetic theory of light, to the marvelous power of radioactivity. "Since the association last met in Canada, (there) has been one of almost unparalleled activity in many branches of physics, and many new and unsuspected properties of matter and electricity have been discovered" [19]. "Investigations made on the unit of positive electricity show that it is of quite a different kind, from the unit of negative, the mass of the negative unit is exceedingly small compared with any atom.... If the positive units have a much greater mass than the negative ones, they ought not to be so easily deflected by magnetic forces when moving at equal speeds; and in general the insensibility of the positive particles to the influence of a magnet is very marked; though there are cases when the positive particles are much more readily deflected... . A knowledge of the mass and size of the units of electricity, the positive and the negative, would give us the material for constructing what may be called a molecular theory of electricity, and would be a starting point for a theory of the structure of matter. ... As it would seem that the units of positive and negative electricity are of very different sizes, we must regard matter as a mixture containing systems of very different types, one type corresponding to the small corpuscle, the other to the large positive unit."

He continues "all substances give out corpuscles, so that we may assume that each atom of a substance contains at least one corpuscle. From the size and the charge on the corpuscle, both of which are known, we find that each corpuscle has $8 \times 10^{-7}$ ergs (ergometers 
or the amount of work done by a force of one dyne exerted for a distance of $1 \mathrm{~cm}$, where $1 \mathrm{erg}=10^{-7}$ joule) of energy.... Now in 1 gram of hydrogen there are about $6 \times 10^{23}$ atoms, so if there is only one corpuscle in each atom, the energy due to the corpuscles in a gram of hydrogen would be $48 \times 10^{16}$ ergs, or $11 \times 10^{19}$ calories. This is more than seven times the heat developed by 1 gram of radium, or than that developed by the burning of 5 tons of coal. Thus, we see that even ordinary matter contains enormous stores of energy; this energy is fortunately kept fast bound by the corpuscles; if at any time an appreciable fraction were to get free, the earth would explode and become a gaseous nebula. The matter of which I have been speaking so far is the material that builds up the earth, the sun, and the stars, the matter studied by the chemist, and which he can represent by a formula; this matter occupies, however, but an insignificant fraction of the universe" [19]. Thomson concludes his speech by pointing out the ongoing nature of scientific discovery with reference to his religious beliefs. "As we conquer peak after peak, we see in front of us regions full of interest and beauty, but we do not see our goal, we do not see the horizon; in the distance tower still higher peaks, which will yield to those who ascend them still wider prospects, and deepen the feeling, whose truth is emphasized by every advance in science, that "Great are the Works of the Lord." [19]. Although the audience would have included a large proportion of lay people over scientists, his address was well received despite a few complaints in local papers about difficulty in comprehending some passages [6].

With the close of the meeting, members of the BAAS delegation and accompanying guests continued their trip across Canada to the Pacific Ocean on September 2. A special train was chartered for the delegation, complete with sleeping accommodation, an observation car, and dining carriages. At various stops along the route, including Regina, Moose Jaw, and Calgary, Thomson met local dignitaries and gave a short speech. The party spent several subsequent days in Vancouver and visited Vancouver Island before their return journey via Edmonton back to Winnipeg, then Toronto, Niagara Falls, Montreal, and eventually Quebec. The return journey took a further 2 weeks, and nearing the end of the journey Thomson was feeling its effects from a lack of sleep [1]. He wrote to Harry Reid from Quebec reflecting on the journey in a letter dated September 24, 1909 [6]. "We had a good deal of amusement on the trip, at one place, Moose Jaw, we were met by a brass band and escorted to a triumphal arch built up of the produce of the district. Concealed in it was a tree stump on which I had to be mounted to make a speech. My speech, however, was very short for the top of the arch was comprised of very heavy bags of flour ... (yet) it shook in a very ominous manner when I got on my stump I expected to have one of the sacks on my head.... I naturally therefore did not indulge in any prolonged oration."
The Thomsons sailed back to England from Quebec aboard the Empress of Britain, where he reflected on the vastness of the North American continent and the struggles of those who worked on the land. "What struck me very forcibly on my visit to the farming district in Canada was the hard struggle the farmers had for the first few years they were on the land.... Another point was the loneliness of their lives in the winter. . . A medical officer told my wife that many of his woman patients deliberately unpicked (the seams of) their dresses in the winter so that they might find something to do in sewing them up again; without this they were liable to go off their heads" [1]. Typical of his travels aboard, J. J. Thomson took more interest in the countryside and its people over particular landmarks or buildings [5].

\section{Final Visit to America}

J. J. Thomson's last visit to America was in the spring of 1923. He had been awarded the Franklin Medal the year prior (Figure 3) but was unable to attend the medal

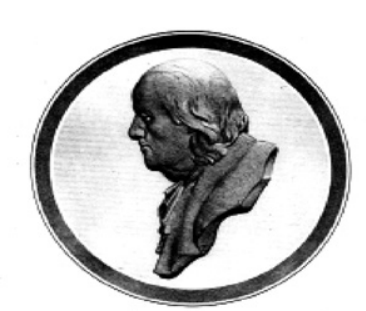

\section{THE ERAWKUIN INSTIHUHE:}

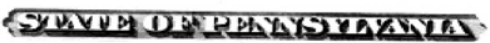

FOIR TIE P'RONIO'TION OF TIIE MECIINIC AIR'T N10.0181)

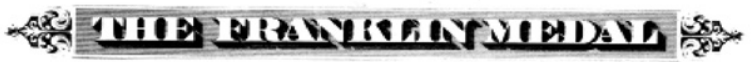

TC)

\section{SIR JDSEPH JOHN THDMSON}

IN RECOGNITION OF THE INNEASLRABLF SERITCE HE HAS RENDERED TO THE WORLD AS TEACHER AND LEADER OF THOUGHT IN THAT DONAIN OF SCIENCE ESPECLALLY RELATED TO A FCNDAMENTAL KXOMLEGE OF ELEGTRIGITY AND THE CONSTITLTION OF IITTER.

PHIL.ADELPHLA, .LAT:ARY 4.1929

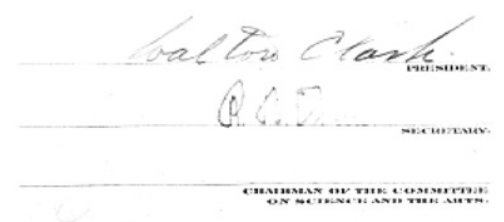

Figure 3. Certificate from the Franklin Institute awarding J. J. Thomson the Franklin Medal on January 4, 1922. 
ceremony. He was instead invited to give a series of lectures at the Franklin Institute in Philadelphia on "The Electron in Chemistry." His wife Rose had also been invited to accompany her husband but she decided not to travel, concerned for her health. Her grandson David Thomson has recalled that even getting Rose to travel to London was a tremendous undertaking [20]. For much of her adult life, she believed she was in poor health, though she suffered mostly from headaches and allergies [20].

Without Rose's company, Thomson's daughter Joan argued she should accompany her aging father as he was likely to lose a pair of pajamas everywhere he stayed if she did not look after him [5]. In late March, they set sail to New York aboard the Majestic and were met by Robert Owens, Thomson's former pupil, who was then Secretary of the Franklin Institute [1]. This time, the Thomsons cleared customs without incident. J. J. Thomson was quick to note the great change in the city since his earlier visit on route to the Plaza Hotel on 5th Avenue where they stayed. "I was very much impressed by the change in New York since my last visit... There were so many new buildings that it seemed to be a new city and one of great beauty and dignity. The sky-scrapers were very much more plentiful and very much higher than before, and this, to my mind, was all to the good. I have always admired sky-scrapers and think that they are the greatest contribution of our generation to architecture."

The group had dinner with Dr. William Eglin, then Vice President of the Franklin Institute, at the Ambassadors Restaurant followed by an evening on Broadway to see the Ziegfeld Follies. The Ziegfeld Follies ran in different guises uninterrupted for nearly 30 years from 1907 until 1931 and featured young women dancing in revealing costumes, together with comedy and burlesque routines [21]. The attractive young women surely caught Thomson's attention but he writes [1] instead of guest Will Rogers, who performed rope tricks and political satire. "His performance was unlike anything I ever saw, before or since. (While) doing tricks with his rope... he jerked out one short sentence after another about some political, social, or indeed any kind of event that was in the papers; (they were) not only excruciatingly funny, but also very sensible. I should think they were quite likely to have considerable effect on politics" [1]. Rogers is famously quoted as saying "I don't tell jokes. I just watch the government and report the facts."

The next day, Thomson was taken from the city to meet Charles Coffin, the former president and chairman of the General Electric Company, at his home in Long Island. The two men discussed research in physics and the electrical industry, viewed Coffin's extensive collection of etchings, and toured his home's large grounds. They took lunch at a nearby country club where Coffin was a member. Thomson later toured the company's laboratories in Schenectady where he met with William Coolidge and Irving Langmuir. Born in Brooklyn, Lang- muir had worked at General Electric for 40 years with a focus on electron density waves in ionised gases or what he called plasma in high vacuum tubes. Thomson has recounted "the staff is very large ... and the annual expenditure is something between $£ 200$ and $300 \mathrm{~K}$.... the experiments they were doing... in many cases were purely scientific in type as those which go on in the Cavendish Laboratory" [6].

While in New York, he also was able to visit the laboratories of the Western Electric Company (Figure 4) that, in 1925, became Bell Laboratories. The laboratories had made extensive studies on the nature of speech and on techniques to record and reproduce sounds. Thomson has recalled "I saw there some most interesting experiments on the effect of taking out the human voice sounds of different pitch (with filters)... By using a number of filters absorbing notes of different pitches, they could find what effect withdrawal of a particular note had upon the voice" [1]. The company was keen to introduce such filters into the telephone system to eliminate noise and improve transmission.

The Thomsons spent a long weekend back in Baltimore again with the Reid family [6]. Newspaper reporters visited the Reids' home for an interview with J. J. Thomson. They were discouraged from intruding until after dinner [6], when he agreed to field a few of their questions. One reporter had heard that the knighted (Sir) Thomson was one of the few men in England who

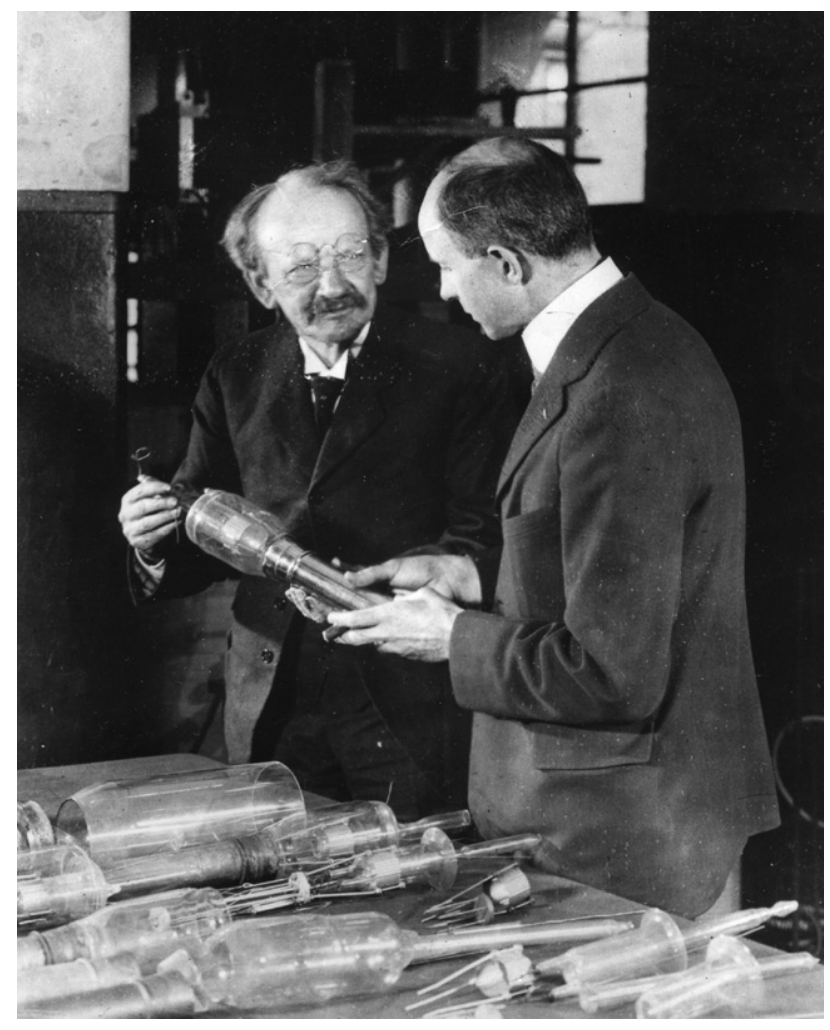

Figure 4. Thomson inspects water-cooled vacuum tubes with F. B. Jewett during his visit to laboratories of the Western Electric Company, the predecessor of Bell Laboratories, March 1923. Source: American Institute of Physics. 
could keep his hat in the presence of the King and asked him if this were true. This misconception likely stems from the story of Quaker William Penn who, while knighted, refused to remove his hat before King Charles II. He reportedly kept both his hat and head.

While in Baltimore, Thomson also met with Robert William Wood, an experimental physicist at Johns Hopkins University, who shared a common interest in botany with J. J. and had published a children's book on the subject [22].

On Tuesday morning, J. J. Thomson set off to Philadelphia to give his lectures at the Franklin Institute. He traveled, at least, like a king, as the institute had placed at his disposal a private train complete with a dining room, two bedrooms, a parlor, kitchen, and a cook and waiter. "All I had to do was to tell the conductor, before I went to bed, where I had to be the next morning and what I would like for breakfast. When I awoke, I found I was at my destination and the breakfast was ready" [1]. An embarrassing incident for the absent-minded man occurred upon his arrival to the Bellevue Stratford Hotel in Philadelphia [1]. On pulling out the key in his pocket at his room, he found it belonged to the Plaza Hotel in New York [6].

\section{Franklin Lectures on the Electron in Chemistry}

Over several afternoons in early April, Thomson presented his five lectures on "The Electron in Chemistry" that were published in the U.S. in the same year [23]. He opened these lectures with a tribute to Benjamin Franklin, in which he noted, "Philadelphia owes ... some of its most important institutions [1]. A prolific inventor, Franklin had been particularly attracted to the idea of harnessing electricity from lightning. Describing his famous kite experiment in a letter of October 1752, Franklin wrote "when rain has wet the kite twine so that it can conduct the electric fire freely, you will find it streams out plentifully from the key at the approach of your knuckle, and with this key a phial, or Leiden jar, maybe charged: and from electric fire thus obtained, spirits may be kindled ... and therefore the sameness of the electrical matter with that of lightening completely demonstrated" [24].

Thomson began his lectures by highlighting how an understanding of the properties of electricity had led to an even greater understanding of the properties of atoms and the nature of chemical bonding bringing the fields of physics and chemistry ever closer together. "It has been customary to divide the study of the properties of matters into two sciences; physics and chemistry. In the past the distinction was a real one, owing to our ignorance of the structure of the atom and molecule.... In the course of the last century, however, the physicists have penetrated into this territory and have arrived at a conception of the atom which indicates the ways in which an atom of one element may differ from that of another" [1]. Rutherford and Bohr's model of the atom, with a concentrated positive nucleus, was very different from Thomson's sphere of positive electrification he had proposed earlier. Thomson writes "in the newer physics, the atom is regarded as made up of a number of electrons arranged round a central charge of positive electricity. The number of the electrons determines the properties of the atom and the action of one atom on another." Although he acknowledges that the electrons are believed to orbit the atom, the complexity of these orbits left him to define stable configurations for which increasing numbers of electrons are positioned symmetrically at the corners of regular polygons about the nucleus. To achieve a stable equilibrium, Thomson reasons that where the number of electrons exceeds eight, any additional electrons must reside in an outer position or shell until a maximum of eight is again reached. In accord with positive ray experiments, he notes that "the atom of neon, which has eight electrons in the outer layer has never been observed with a negative charge, while a negative charge is common on atoms of hydrogen, chorine, carbon, and oxygen." Thomson writes that unlike a neutral halogen atom, such as chlorine, neon has been found to lose two electrons so that it can combine with two hydrogen atoms or one atom of oxygen; the former indistinguishable from the heavy isotope of neon. If a neutral neon atom were combined with an atom of hydrogen, the compound $\mathrm{NeH}$ would be formed, which would carry a unit charge of positive electricity. He notes that Aston has observed a line corresponding to a compound with a weight of 21 in his mass spectrograph and suggests that these molecules too may account for such species. Well into the 1920s, Thomson had some misgivings [25] about the existence of heavy isotopes despite Aston's published results [26]. In 1921, Aston argued that neon undoubtedly has two members of mass 20 and 22 and a third doubtful one of mass 21.

Dinners over three nights were held in Thomson's honor. He gave an additional two addresses at Haverford and Swarthmore colleges and also visited Bryn Mawr College for women near Philadelphia. He also revisited Yale University to open the new Sterling Chemistry Laboratory there. Introduced to the large audience of chemists assembled at Yale as the most eminent of living physicists, Thomson commenced his address with deference to Josiah Willard Gibbs, a physical chemist who provided a theoretical foundation for chemical thermodynamics. He then challenged the audience with the rhetorical question "who can say what is physics and what is chemistry?" [27]. He argued that no wall of ignorance now separates physics and chemistry and that when the physicist had finished determining the properties of the atom, it strongly resembled that theorized the chemists. Yet he was also clear to delineate the fields. While not underrating the sensitivity of chemical analysis, his preference was for physics where it was easy, he attested, to detect a single atom. By electrifying (ionizing) atoms, they can be placed under control 
because they can be given as much energy as desired, and energy counts in detection [27].

Thomson then returned to New York to rejoin his daughter for their homeward journey to England. They left America for the last time aboard the Homeric, their arms loaded with presents of flowers and boxes of chocolates [6], a bounty they successfully defended with U.S. customs. They experienced bad weather and a rough passage in their voyage though "neither my daughter nor I suffered any inconvenience from it." The Homeric was a ship not known for fast passage, but fortunately was remarkably steady in rough seas. Approaching 70 years, Thomson was to travel abroad less frequently after his return.

\section{Impressions of University Education and Philanthropy in America}

J. J. Thomson's 70th birthday was celebrated at the annual Cavendish dinner on December 18, 1926. He was presented two silver caskets and an address bearing 230 signatures of his disciples by the then Director Ernest Rutherford. Tributes from around the world were received, including one from Alois Kovarik, a Professor of nuclear physics at Yale University. Kovarik wrote: "we Americans owe a debt of gratitude to (the Cavendish Laboratory) for aiding and developing the spirit of research in physics in America. There is scarcely a physicist in America who has not been a pupil of Sir Joseph or else a pupil of one of his pupils.... To these men, Sir Joseph was made known not only as a physicist who opened the fields of electronics and of atomic structure, but also as a most congenial and sympathetic man. To them also he soon became known simply as J. J." [6].

Thomson had been most impressed by the level of philanthropy in the United States and its benefit to American universities. "One reason why so many laboratories have been given to the Universities no doubt is that there are many rich men in America; another, and I think, perhaps an even stronger one is the feeling in regard to money that exists in that country. I do not know of any country in the world where less deference is paid to mere wealth. In America, wealth can in some ways do very little; it can't buy social distinction. ... If a rich man wishes to gain the esteem of his fellow countrymen, he does it by devoting some of his money for public use.... (As) an example, a man came to me and said "I want to do something for the molecule and the atom." This spirit, I think, is one great asset America possesses over us" [6].

He also noted the different approach to education in the U.S. over Britain, where specialization begins earlier. "There is one point, however, where I think the advantage is on our side and that is our system of secondary and tertiary education. (Students in America) come away from school with a kind of vague interest in a good many things but they do not come away with trained minds ... to take science at the university (and) insufficient knowledge of mathematics" [6]. He concludes "I hope we shall stick to that advantage because, judging by what I see of the state of industries in America, we shall need every advantage if we are to hold our own in competition" [6]. The broader educational university experiences in America, over the more focused studies in Britain, survive to this day.

J. J.'s latter years were increasingly focused on his activities as Master of Trinity College, though he continued to work and publish articles well into the 1930s (Figure 5) [28, 29] including reporting on the existence of two forms of tritium $\left({ }^{3} \mathrm{H}\right)$ as confirmed by Aston's mass spectrograph. Despite Aston's work, it has not escaped the attention of this author, or another [30], that Aston is mentioned only fleetingly in Thomson's Recollections [1] and his name does not appear in the index of names [21].

Thomson traveled overseas again in 1933 on an Atlantic cruise to Madeira Island and Lisbon with his daughter Joan [5, 6]. Madeira has been referred to as a "floating garden." The island's natural beauty would have appealed to J. J. and was a likely catalysis for the Thomson's trip. In later life, he never tired of conversations on wild flowers, recalling the names of flowers his daughter had spotted and described to him in her travels about Cambridge while he rested at home [6]. He spent his final days in the garden of the Master's Lodge. Reflecting on its beauty, he puzzled over the

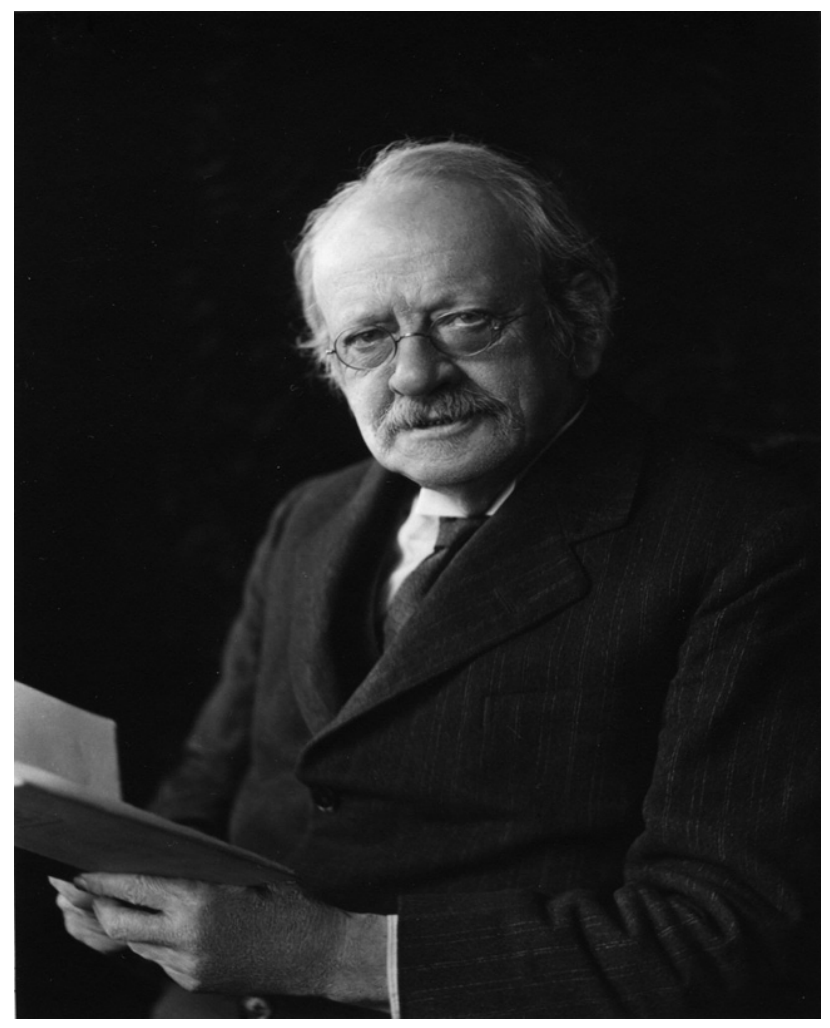

Figure 5. J. J. Thomson in 1933. Source: American Institute of Physics. 
mysteries of plant growth in the natural world, a world his own experiments on the nature of atomic particles and the structure of the atom would eventually begin to reveal.

\section{References}

1. Thomson, J. J. Recollections and Reflections, G. Bell and Sons Ltd., London, 1936.

2. Thomas J. M. J. J.Thomson: Winner of the Nobel Prize for Physics 1906. Angew. Chem. Int. Ed. 2006, 45, 6797-6800.

3. Achinstein, P. Who Really Discovered the Electron? In Histories of the Electron: The Birth of Microphysics, Buchwald, J. Z.; Warwick, A., Eds.; Massachusetts Institute of Technology Press: Cambridge, MA, 2001.

4. Thomson, G. P. J. J. Thomson and the Cavendish Laboratory in His Day; Nelson and Sons Ltd., London, 1964.

5. Thomson, J.; Thomson, G. P. J. J. Thomson as We Remember Him Notes Records Royal Soc. London 1957, 12, 201-210.

6. Rayleigh, Lord (Strutt, R. J.) The Life of Sir J. J. Thomson, O.M., Sometime Master of Trinity College; Cambridge University Press: Cambridge, UK, 1942.

7. Washington Times article Assassin Fired the Bomb: New Light on the Mysterious Explosion; October 23, 1896.

8. Wikipedia entry: http://en.wikipedia.org/wiki/Harry_Fielding_Reid.

9. Memorial Book of the Sesquicentennial Celebration of the Founding of the College of New Jersey and of Ceremonies Inaugurating Princeton University; Charles Scribner's Sons: New York, NY, 1898.

10. Leitch, A. A Princeton Companion; Princeton University Press: Princeton, PA, 1978.

11. Thomson J. J. The Discharge of Electricity through Gases: Lectures Delivered on the Occasion of the Sesquicentennial Celebration of Princeton University; Scribner's Sons: New York, NY, 1898.

12. Crew, H. Review: Professor J. J. Thomson's Work on the Structure of the Atom. Astrophys. J. 1900, 11, 170-174.
13. Thomson, J. J. Electricity and Matter; Charles Scribner and Sons: New York, 1904.

14. Thomson, J. J. Electricity and Matter (1904). Kessinger Publishing: Whitefish, MT, 2007

15. Thomson, J. J. Structure of the Atom. Philosoph. Mag. 1904, 7, 237-265.

16. Thomson, J. J. Over the Number of Corpuscles in an Atom. Philosoph. Mag. 1906, 11, 769-781.

17. Miller, G. A. The Winnipeg. Meeting of the British Association for the Advancement of Science. Science 1909, 30, 351-352.

18. Dietrich, S.; Klassen, S. Physics Comes to Winnipeg: The 1909 Meeting of the British Association for the Advancement of Science. Proceedings of the Second International Conference on Story in Science Teaching; Munich, Germany, 2008.

19. Thomson, J. J. Address of the President of the British Association for the Advancement of Science. Science 1909, 30, 257-279.

20. Thomson, D. Foreword. In J. J. Thomson and the Discovery of the Electron Davis, E. A.; Falconer, I. J. Eds.; Taylor and Francis: London, 1999.

21. Bloom, K. Broadway: Its History, People, and Places: An Encyclopedia, 2nd ed.; Taylor and Francis: London, 2004.

22. Wood, R. W. How to Tell the Birds from the Flowers and Other Woodcuts, a Manual of Flornitology for Beginners, 1st ed.; Paul Elder and Company: San Francisco, CA, 1907.

23. Thomson, J. J. The Electron in Chemistry. Franklin Institute, Philadelphia, 1st ed.; J. B. Lippincott Co. Press: Philadelphia, PA, 1923.

24. Franklin, B. A Letter of Benjamin Franklin, Esq. to Mr. Peter Collinson, F.R.S. concerning an Electrical Kite. Philosoph/Trans. 1752, 47, 565-567.

25. Thomson, J. J.; Aston, F. W.; Soddy, F.; Merton, T. R.; Lindemann F. A. Discussion on Isotopes. Proc. Royal Soc. Lond. Series A 1921, 99, 87-104.

26. Aston, F. W. Mass Spectra of Chemical Elements. Philosoph. Mag. 1921, 42, 140-144.

27. Davies, W. The Master of Physics Discusses Chemistry. Ind. Eng. Chem 1923, 15, 466.

28. Thomson, J. J. Two Kinds of H3. Philosoph. Mag. 1934, 17, 1025-1030.

29. Thomson, J. J. Electronic Waves. Philosoph. Mag. 1939, 27, 1-32.

30. Dahl, P. F. Flash of the Cathode Rays, Institute of Physics Publishing Ltd.: Bristol, UK, 1997. 